\title{
Evaluation of haematological, hepatic and renal functions of petroleum tanker drivers in Lagos, Nigeria.
}

\author{
Olufunsho Awodele, Ademola A. Sulayman and Alade Akintonwa
}

Department of Pharmacology, Therapeutics \& Toxicology, College of Medicine, University of Lagos, PMB 12003, LagosNigeria

\begin{abstract}
Background: Hydrocarbons which are among the major components of petroleum products are considered toxic and have been implicated in a number of human diseases. Tanker drivers are continuously exposed to hydrocarbons by inhalation and most of these drivers do not use protective devices to prevent inhalation of petroleum products; nor do they visit hospital regularly for routine check-up.

Objective: In view of this occupational hazard, we investigated the haematological, renal and hepatic functions of workers of petroleum tankers drivers in Lagos, Nigeria.

Method: Twenty-five tanker drivers' and fifteen control subjects were randomly selected based on the selection criteria of not smoking and working for minimum of 5 years as petroleum tanker driver. The liver, renal and haematological parameters were analyzed using automated clinical and haematological analyzers while the lipid peroxidation and antioxidant level tests were assayed using standard methods.

Results: There were significant $(\mathrm{p} \leq 0.05)$ increases in the levels of serum alanine amino transferase $(31.14 \pm 13.72$; $22.38 \pm 9.89)$, albumin $(42.50 \pm 4.69 ; 45.36 \pm 1.74)$ and alkaline phosphatase $(84.04 \pm 21.89 ; 62.04 \pm 23.33)$ of petroleum tanker drivers compared with the controls. A significant $(\mathrm{p} \leq 0.05)$ increase in the levels of creatinine, urea and white blood cells of the tanker drivers, compared with the controls, were also obtained.

Conclusion: The results have enormous health implications of continuous exposure to petroleum products reflected hepatic and renal damage of petroleum tanker drivers. Therefore, there is need for this group of workers to be sensitized on the importance of protective devises, regular medical checkup and management.
\end{abstract}

Key words: petroleum tanker drivers, hydrocarbons, renal, liver functions, oxidative stress.

African Health Sciences 2014;14(1): 178-184 http://dx.doi.org/10.4314/ahs.v14i1.27

\section{Introduction}

Hydrocarbons which are among the major components of petroleum products that tanker drivers are continuously exposed to, play a major role in life globally ${ }^{1}$. Even though hydrocarbon products are useful, a some hydrocarbons are toxic and have beenimplicated in a number of diseases ${ }^{2}$. In Nigeria, more than $10 \%$ of the population has continuous exposure to hydrocarbon products: notably petroleum and this has been implicated in a number of diseases, Health problems and environmental degradations ${ }^{3}$. Indiscriminate usage of these petroleum products domestically and industrially and their associated health problems is a source of concern that should be investigated.

\section{Corresponding author:}

Olufunsho Awodele

Department of Pharmacology, Therapeutics \&

Toxicology, College of Medicine, University

of Lagos, PMB 12003, Lagos-Nigeria

Email:Awodeleo@gmail.com

Tel:+234-8023624044
Polycyclic aromatic hydrocarbons (PAHs) are form of hydrocarbons that consist of fused aromatic rings ${ }^{4}$. They are present in petroleum oil, coal and tar deposits, and are produced as by-products of fuel burning. PAHs are of concern because some components have been identified as carcinogenic, mutagenic and teratogenic. Exposure to PAHs is associated with a high risk of renal dysfunction and cancer. Many researchers have confirmed nephrotoxicity with chronic exposure of PAHs ${ }^{5}$. Experimental data have demonstrated both glomerular and tubular toxicity ${ }^{6-7}$. Systemic exposure by inhalation has been demonstrated by detection of the pyrene metabolite, 1-hydroxylpyrene in urine of exposed subjects ${ }^{8}$. In a cross sectional study by Taberghar occupational medicine associates ", wood fetching workers exposed to creosote had an increased incidence of haemeturia, although renal function of this cohort was not documented. Interestingly, eosinophia in $8 \%$ of the workers was also observed ${ }^{10}$. However, the volatile component in creosote is naphthalene and addiction to naphthalene exposure has been associated with chronic renal failure. Ravnskov et al, 2005 has 
shown that hydrocarbons may induce renal injury by combining with renal proteins and artery as heptanes to induce auto-immunity against renal cells ${ }^{5}$. It may also modify T-cell function leading to an unfavorable cytokine profile and predisposing to $\mathrm{T}$-cell mediated renal injury.

Hydrocarbons are also known to be hepatotoxic ${ }^{11}$. The hepatotoxicity results after hydrocarbon undergoes phase 1 metabolism, thereby inducing free radicals formation. These free radicals subsequently bond with hepatic macromolecules and ultimately cause lipid peroxidation. This metabolite creates a covalent bond with the hepatic macromolecules, thereby initiating lipid peroxidation ${ }^{12}$. Liver function tests can be abnormal within 24 hours after ingestion and clinically apparent jaundice can occur within $48-96$ hours ${ }^{12}$. It has also been documented that prolonged exposure to certain aromatic hydrocarbons especially PAHs can lead to an increased risk of aplastic aneamia, multiple myeloma and acute myelogenous leukemia ${ }^{13}$. Haemolysis has been reported following the acute ingestion of various type of aromatic hydrocarbons ${ }^{14}$. The toxicity of hydrocarbons is directly related to their physical properties, specifically the viscosity, volatility, surface tension and chemical activity of the side chains ${ }^{15}$.

It is quite clear that one of the major occupational hazards of petroleum tanker drivers is continuous unintentional inhalation of hydrocarbons which is the major components of petroleum product. Most of these drivers do not use protective devices to prevent inhalation of petroleum products; nor do they visit hospital regularly for routine medical check-up. Worse still, most of the drivers have been on this job for a long period of time.

In view of the above occupational risks that are associated with the petroleum tanker drivers' job, this study aimed to investigate the haematological, renal and hepatic functions of these workers in Lagos. This s study might be followed by tangible interventional measures.

\section{Methods}

\section{Subject selection}

A comprehensive letter stating the goals of this study was written to the Association of petroleum tanker drivers in Lagos to obtain their permission to undertake this study. The consent of individual petroleum tanker driver was sought and there after a well structured questionnaire containing the socio-demographical data, safety knowledge and health status were distributed to the consented subjects. Out of the Four hundred and fifty questionnaires self distributed, three hundred and four of the questionnaires were however completely and adequately filled. Twenty-five of the above subjects were randomly selected based on the selection criteria of working for minimum of 5 years as petroleum tanker driver. Also, fifteen matched control subjects who were not known to be smokers nor continuously exposed to any source of hydrocarbon were carefully selected. The study was approved by the Department of Pharmacology, College of Medicine, University of Lagos Postgraduate Ethics committee and was performed in accordance with the standards laid down in the 1964 Declaration of Helsinki and its later amendments. (REF)

\section{Blood sample collection}

The blood samples of the participants were carefully collected by an experienced nurse into lithium heparin and EDTA bottles to obtain the serum and plasma respectively. The serum samples were used for chemistry analysis (liver function, renal function, lipid peroxidaation and antioxidant level tests) and the plasma samples were used for the assessment of the haematological parameters.

\section{Liver function and renal function test}

Liver function parameters - serum alanine amino transferase (ALT), aspartate amino transferase (AST), albumin (ALB), alkaline Phosphatase (ALP); and renal function parameters (creatinine and urea) were analyzed using the fully automated clinical chemistry analyzer (Hitachi 912, Boehringer Mannheim, Germany).

\section{Haematological parameters}

The haematological parameters (white blood cell, red blood cell, haematocrit, platelet, neutrophil and lymphocyte) were analysed using fully automated clinical haematological analyzer (Boehringer Manuheim, Germany).

Briefly, the analysis of liver enzymes, creatinine, urea, and haematological automated operation procedures involve switching on the machine and thereafter proceed to initial process of checking the reagent and sample probes using the ABS in the flex for the reagent. The sample (serum or plasma) is then inputted and the machine automatically run the samples and generates appropriate results. 
Measurement of antioxidant ensymes and MDA levels

Oxidative stress parameters (Malondialdehyde - MDA), superoxide dismutase (SOD) and reduced glutathione (GSH) were determined using the methods of Beers and Seizer ${ }^{16}$ and Beuge and Aust ${ }^{17}$. The methodology used is described briefly below.

Determination of superoxide dismutase activity (EC 1.15.1.1) Serum superoxide dismutase activity was determined by its ability to inhibit the auto-oxidation of epinephrine determined by the increase in absorbance at $480 \mathrm{~nm}$. The reaction mixture $(3 \mathrm{ml})$ contained $2.95 \mathrm{ml} 0.05 \mathrm{M}$ sodium carbonate buffer $\mathrm{pH} 10.2,0.02 \mathrm{ml}$ of serum and $0.03 \mathrm{ml}$ of epinephrine in $0.005 \mathrm{~N}$ hydrochloric acid. The reference cuvette contained $2.95 \mathrm{ml}$ buffer, $0.03 \mathrm{ml}$ of substrate (epinephrine) and $0.02 \mathrm{ml}$ of water. Enzyme activity was calculated by measuring the change in absorbance at $480 \mathrm{~nm}$ for $5 \mathrm{~min}$. $\sum=4020 \mathrm{M}^{-1} \mathrm{~cm}^{-1}$

\section{Reduced glutathione determination (EC 2.5.1.18)}

The reduced glutathione content of serum as nonprotein sulphydryls was estimated by adding 10\% tricarboxilic acid to the sample and $1.0 \mathrm{ml}$ of the mixture was treated with $0.5 \mathrm{ml}$ of Ellmans reagent (19.8mg of 5,5-dithiobisnitro benzoic acid in $100 \mathrm{ml}$ of $0.1 \%$ sodium nitrate) and $3.0 \mathrm{ml}$ of phosphate buffer (0.2M, pH 8.0). The absorbance was read at $412 \mathrm{~nm} . \Sigma$ $=1.34 \times 10^{4} \mathrm{M}^{-1} \mathrm{~cm}^{-1}$
Determination of lipid peroxidation (EC 202-974-4) [26-27] Malondialdehyde an index of lipid peroxidation was determined by adding $1.0 \mathrm{ml}$ of the sample to $2 \mathrm{ml}$ of (1:1:1 ratio) thiobarbituric acid $0.37 \%, 0.24 \mathrm{~N}$ hydrochloric acid and 15\% tricarboxylic acid reagents. Tricarboxylic acid- thiobarbituric acid-hydrochloric acid reagents boiled at $100^{\circ} \mathrm{C}$ for $15 \mathrm{~min}$, and allowed to cool. Flocculent materials were removed by centrifuging at $3000 \mathrm{rpm}$ for $10 \mathrm{~min}$. The absorbance read at $532 \mathrm{~nm}$ against a blank. Malondialdehyde was calculated using the molar extinction coefficient for Malondialdehydethiobarbituric acid complex of $1.56 \times 10^{5} \mathrm{M}^{-1} \mathrm{CM}^{-1}$.

The protein content was measured by buiret method with bovine serum albumin (BSA) as standard.

\section{Statistical analysis}

Results are presented as mean \pm S.E.M. Statistical significance between the control groups and the test groups was analyzed by the student's $t$-test at $p<0.05$.

\section{Results}

Table 1 results showed the highest age distribution of the studied subjects to be between 41-45 years. Eight $(32 \%)$ of the subjects have been working as petroleum tanker drivers for between 11-15 years. Most (56\%) of the subjects had no training (education) and $68 \%$ had no safety knowledge.

Table 1: Socio-demographic data of Petroleum Tanker Drivers

Age(years)
$30-35$
$36-40$
$41-45$
ABOVE 45
Total
Working
experience(years)
5-10
$11-15$
$16-20$
ABOVE 20
Total
Education
Formal Training
Informal Training
No Training
Total
Safety knowledge
Yes
No
Don't care
Total

Frequency
2
9
10
4
25

Percentage $(\%)$
8
36
40
16
100

$\begin{array}{cc}6 & 24 \\ 8 & 32 \\ 4 & 16 \\ 7 & 28 \\ \mathbf{2 5} & \mathbf{1 0 0} \\ & \\ 4 & 16 \\ 7 & 28 \\ 14 & 56 \\ \mathbf{2 5} & \mathbf{1 0 0} \\ & \\ 3 & 12 \\ 17 & 68 \\ 5 & 20 \\ \mathbf{2 5} & \mathbf{1 0 0}\end{array}$


Skin infection and rashes were common health pain and eye itching $(32 \% ; 24 \%)$ respectively. problems of the petroleum tanker drivers (64 The larger proportion of the subjects $(68 \%)$ $\%$ ). A few of the subjects had regular chest had high blood pressure above $140 / 90 \mathrm{~mm} \mathrm{Hg}$ (Table 2).

Table 2: Health Status Parameters of Petroleum Tanker Drivers

$\begin{array}{lcc}\text { Chest pain and cough } & \text { Frequency } & \text { Percentage (\%) } \\ \text { Regular } & 8 & 32 \\ \text { Occasional } & 11 & 44 \\ \text { Rare } & 6 & 24 \\ \text { Total } & \mathbf{2 5} & \mathbf{1 0 0} \\ \text { Skin rashes and infection } & & 64 \\ \text { Regular } & 16 & 24 \\ \text { Occasional } & 6 & 12 \\ \text { Rare } & 3 & \mathbf{1 0 0} \\ \text { Total } & \mathbf{2 5} & 24 \\ \text { Eye itching and infection. } & & 64 \\ \text { Regular } & 6 & 12 \\ \text { Occasional } & 16 & \mathbf{1 0 0} \\ \text { Rare } & 3 & \\ \text { Total } & \mathbf{2 5} & 32 \\ \text { B.P measurement } & & 68 \\ \text { Normal(Below } 140 / 90 \mathrm{mmHg}) & 8 & \mathbf{1 0 0}\end{array}$

Table 3 shows the relationship between length of exposure and the frequency of some health status parameters of petroleum tanker Drivers.

Table 3: Relationship between length of exposure and the health status parameters of Petroleum Tanker Drivers

Frequency of Chest Pain, Skin rashes \& Infections Eye Itching \& Infection Blood Pressure

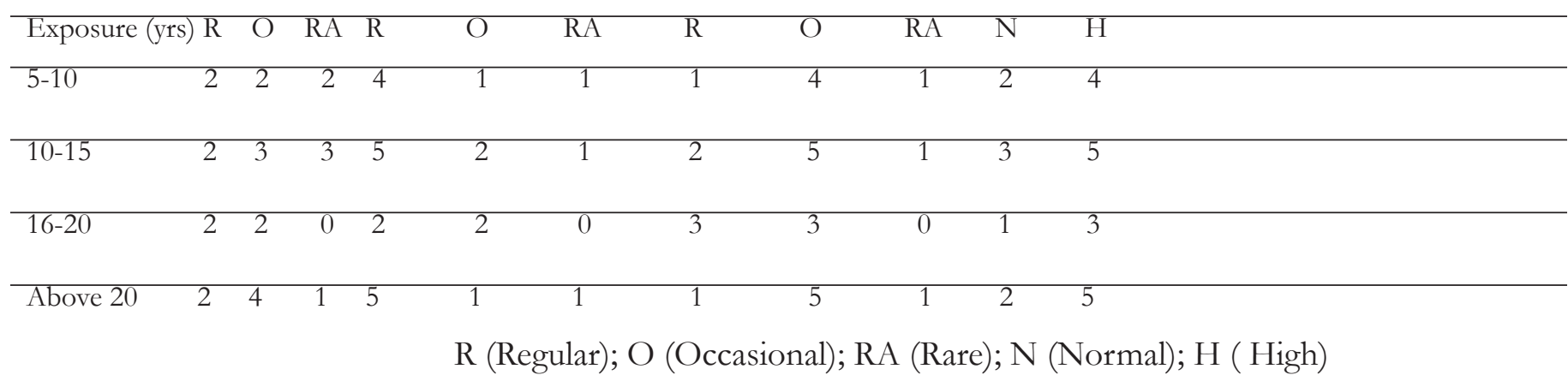

The frequency of distribution of chest pain, skin rashes and infections and eye itching and infection with length of exposure (years) were inconsistent.
Table 4 showed statistically significant decrease $(\mathrm{p} \leq 0.05)$ between the MDA (42.66 \pm 0.05 ; $39.60 \pm 2.61)$ and SOD $(5.51 \pm 0.47 ; 4.77 \pm 0.12)$ levels of the petroleum tanker drivers and control subjects. 
Table 4: Lipid peroxidation and antioxidant parameters in Petroleum Tanker Drivers and Control subjects

\begin{tabular}{lccc}
\hline Groups & MDA & SOD & GSH \\
\hline Control & $39.61 \pm 2.61$ & $4.77 \pm 0.12$ & $1.53 \pm 0.13$ \\
\hline Exposed & $42.66 \pm 0.05^{*}$ & $5.51 \pm 0.47^{*}$ & $1.58 \pm 0.26$ \\
\hline
\end{tabular}

$* \mathrm{P} \leq 0.05$ between exposed and control subjects

MDA, malondialdehyde (U/g proteins); GSH, reduced glutathione (U/g proteins); SOD, Superoxide dismutase (U/g proteins)

There was a significant $(\mathrm{p} \leq 0.05)$ increase in the levels between the petroleum tanker drivers and the control

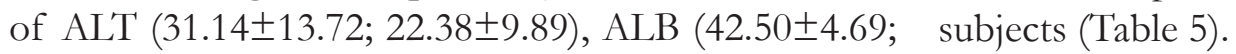

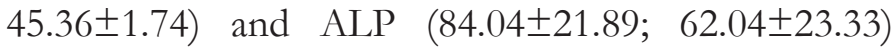

Table 5: Hepatic function enzymes markers in petroleum tanker drivers and control subjects

\begin{tabular}{|c|c|c|c|c|}
\hline Groups & AST (U/L) & ALT (U/L) & ALB (U/L) & $\operatorname{ALP}(\mathrm{U} / \mathrm{L})$ \\
\hline Control & $39.45 \pm 6.60$ & $22.38 \pm 9.89$ & $45.36 \pm 1.74$ & $62.04 \pm 23.33$ \\
\hline Exposed & $38.76 \pm 17.81$ & $31.14 \pm 13.72^{*}$ & $42.50 \pm 4.69^{*}$ & $84.04 \pm 21.89 *$ \\
\hline
\end{tabular}

$\mathrm{P} \leq 0.05$ between exposed and control subjects

*Serum alanine amino transferase (ALT), Aspartate amino transferase (AST), Albumin (ALB), Alkaline Phosphatase (ALP)

The results in table 6 showed significant $(\mathrm{p} \leq 0.05)$ increase in the levels of creatinine $(116.72 \pm 15.65 ; 105.74$ $\pm 8.54)$ and urea $(5.04 \pm 1.21 ; 4.40 \pm 0.91)$ between the exposed subjects (petroleum tanker drivers) and the controls.

Table 6: Creatinine and urea level in Petroleum Tanker Drivers and Control subjects

\begin{tabular}{lcc}
\hline Groups & Creatinine $(\mathrm{umol} / \mathrm{L})$ & Urea \\
\hline Control & $105.74 \pm 8.54$ & $4.40 \pm 0.91$ \\
\hline Exposed & $116.72 \pm 15.65^{*}$ & $5.04 \pm 1.21^{*}$ \\
\hline & $* \mathrm{P} \leq 0.05$ between exposed and control subjects
\end{tabular}

The haematological parameters (table 7) level of neutrophil of the exposed subjects showed significant $(\mathrm{p} \leq 0.05)$ increase in the $(49.97 \pm 11.13)$ compared with the control level of WBC of the petroleum tanker drivers (41.97 \pm 8.33$)$. The results further showed a $(6484.00 \pm 1716.30)$ as compared with the significant decrease $(\mathrm{p} \leq 0.05)$ in the lymphocytes

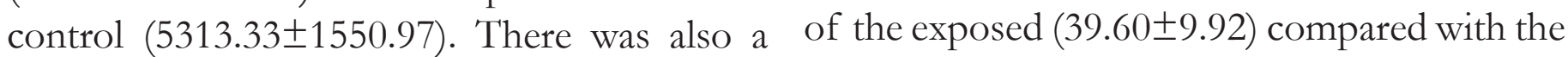
corresponding non significant increase in the control (45.75 \pm 6.73$)$. 
Table 7: Haematological parameters in petroleum tanker drivers and control subjects

\begin{tabular}{|c|c|c|c|c|c|}
\hline Groups & WBC & RBC & НCТ & NEUT & LYMP \\
\hline Control & $5313.33 \pm 1550.97$ & $4.6 \times 10^{6} \pm 4.2 \times 10^{6}$ & $40.14 \pm 2.89 \quad 2.1 \times 10^{5} \pm 63438.91$ & $41.97 \pm 8.33$ & $45.75 \pm 6.73$ \\
\hline
\end{tabular}

$* \mathrm{P} \leq 0.05$ between exposed and control subjects

WBC=White blood cell (thousands/1); RBC=Red blood cell (millions/l); HCT= Haematocrit (\%); PLT=Platelet (/UL);

NEUT=Neutrophil; LYMP=Lymphocyte

\section{Discussion}

The use of petroleum products by humans is inevitable. They are used for various reasons at home, in manufacturing and petrochemical industries ${ }^{18}$. Previous studies in Nigeria on the potential health hazards of petroleum products in humans had concentrated on petrol station attendants ${ }^{18-19}$. Their findings show that inhalation of petroleum products could cause hepatic and renal impairment and reduction in the haematological indices. Prior to these studies, animal studies had shown petroleum products are toxic to the bone marrow, lymph nodes, spleen and haematological parameters ${ }^{20}$. Hitherto, there has been no study to the potential health risk of petroleum products on petroleum tanker drivers. The drivers are usually on the road for days transporting petroleum products from one state to the other and thus are continuously exposed to this hazardous agent.

The results obtained from this study showed that most (40\%) of the petroleum tanker drivers were between the age of 41 and 45 years and a large proportion (32 $\%$ ) of these workers have spent between 11-15 years on this job. The survey revealed that the drivers $(56 \%)$ neither had training (education) nor safety knowledge $(68 \%)$. There was a high prevalence of skin rash (64 $\%$ ) and hypertension (68\%) among the petroleum tanker drivers. The elevated blood pressure among most of the drivers may be due to work overload and stress. The findings from this study affirmed this statement as there were length of exposure (years) dependent significant increase $(\mathrm{p} \leq 0.05)$ in the blood pressure of petroleum tanker drivers. The high level of blood pressure could thus be an accumulation of work overload, stress and increase length of exposure to hydrocarbons as earlier mentioned. This assertion may be correct and appropriate because increases in blood pressure often occur among individuals or workers that are always over worked with long duration of time on the job. However, the no correlation in the frequency of distribution of chest pain, skin rashes and infections and eye itching and infection with length of exposure to hydrocarbons may be expected. All these health parameters are often affected with even short term of exposure to hydrocarbons as they are more of inflammatory responses.

The significant $(p \leq 0.05)$ increase in the creatinine and urea levels of the petroleum tanker driver compared with the control in this our study is in agreement with the findings by Nwanjo and Ojiako ${ }^{19}$ who petrol attendants to have altered renal function values. There was also significant $(\mathrm{p} \leq 0.05)$ increase in the level of serum alanine amino transferase (ALT) and aspartate amino transferase (AST) of the petroleum tanker drivers compared with the control subjects. This observation may be due to the fact that hydrocarbons which are a major component of petroleum products are potent inducers of cytochrome $\mathrm{P} 450$ that could lead to biological consequences. The report of Nwanjo and Ojiako ${ }^{19}$ also showed increased levels of hepatic enzymes in the studied subjects. The haematological findings showed a significant increase $(p \leq 0.05)$ in the white blood cells and decrease $(p \leq 0.05)$ in lymphocytes of the tanker driver compared with the controls. These observations may reveal ongoing infection which could have led to skin rashes and infection experienced by the tanker drivers as a result of altered immunity. The work of Iwuanyanwu et $\mathrm{l}^{21}$ also showed altered haematological parameters in rats fed with food contaminated with petroleum products. The tanker drivers investigated in this study showed a significant increase $(p \leq 0.05)$ in their lipid peroxidation level compared with the control subjects. It may be the petrochemical activated metabolites that react with some cellular components such as membrane lipids to produce lipid peroxidation products ${ }^{22}$ which may lead to membrane change and tissue damage. The increase in lipid peroxidation may also be responsible for the renal and hepatic damage observed in the petroleum tanker drivers as seen in this study. 


\section{Conclusion}

There are enormous health implications of continuous exposure to petroleum products as seen in the hepatic, renal and lipid peroxidation biomarkers elevation of petroleum tanker drivers in this study. There is need for this group of workers to be sensitized on the need for regular medical checkup, management and the use of appropriate protective gear.

\section{Acknowledgement}

The authors acknowledge the Association of Petroleum Tanker Drivers in Lagos for their co-operation in this work.

\section{Conflict of Interest:}

The authors have no conflict of interest to declare.

\section{References}

1. Fetzer J.C. "The Chemistry and Analysis of large polycyclic aromatic hydrocarbon"Polycyclic aromatic compounds (NY:wiley);2000; 27:143

2. Moore S. For shell, "Nigerian Debade isn`t the end of the line": Danger lurks in Ogboni land for people and pipeline, but the place Beckons, WALL ST; 2002. 3. Armstrong B. Hutchinson E. Unwin J. Fletcher T. Lung cancer risk after exposure to polycyclic aromatic hydrocarbons:Review and meta-analysis Environ Health perspect; 2004; 112(9):970-8

4. Luch A. The carcinogenic effects of polycyclic aromatic hydrocarbons. London: Imperial College Press ISBN 1-86094-4175;2005

5. Ravnskor U. Experimental glomerulonephritis induced by hydrocarbons exposure. A systemic review. BMC nephrology; 2005; 6:15

6. Nauz A. Alejandro N.F. Falahatpisheh M.H. Kerzee J.K. Roths J.B. Ramos K. S . Distruption of glomerular cell-cell and cell-matrix interactions in hydrocarbon nephropathy. American journal of physiology; 2005; 289(6); F1291-303

7. Tang Y. Donnelly K.C. Tiffany-castiglioni E. Mumtaz M.M.Neurotoxicity of polycyclic aromatichydrocarbons and simple chemical mixtures.Journal of toxicology and Environmental health; 2003; 66(10); 919-940

8. Elovaara E. Heikkila P. Pyy L. Mutanen P. Riihimaki V. Significance of dermal and respiratory uptake in creosote workers;exposure to polycyclic aromatic hydrocarbons and urinary excrection of 1-hydroxypyrene. Occupational and Environmental
Medicine;1995; 52 (3):196-203.

9. TOMA . Tars are complex combinations of polycyclic aromatic hydrocarbons exposure levels from any source;1982

10. Jensen U. William B. The origin of the circle symbol aromaticity of journal of chemical education; 2009; 86(4):411-528

11. Sofer S. Milder L. and Gorodischer R. Acute pancreatitis in children following exposure to polycyclic aromatic hydrocarbons; 2003

12. Halliday A.N, Pettke T and Rea D.K. Remediation of polycyclic aromatic hydrocarbon. contaminated from incomplete combustion of hydrocarbon fuels; 2004.

13. Krieger J.A, Bols N.C, Brubacher J. L, Ganassin R.C and Lee L.E. Effect of polycyclic aromatic hydrocarbon on the immune systems; 2001.

14. Bronstein A.C, Spyker D.A, Cantilena L.R, Green J. Rumack B.H, Heanl S.E . Annual Report of the American Association of poison(Know how to treat hydrocarbon poisoning-patient care); 2006

15. Lifshitz M, Sofer S, Gorodischer R. Hydrocarbon poisoning in children: a 5-year retrospective study. Wilderness Environ Med; 2003;14(2):78-82.

16. Beers RF, Seizer IW. A spectrophotometric method for measuring breakdown of hydrogen peroxide by catalase. Journal of Biological Chemistry,1952;195, 133

17. Beuge JA, Aust SD. The thiobarbituri acid assay. Methods Enzymol; 1978; 52, 306.

18. Okoro AM, Ani E.J, Ibu J.O, Akpogomeh B.A. Effect of petroleum products inhalation on some haematological indices of fuel attendants in calabar metropolis, Nigeria. Nigerian Journal Of Physiological Sciences; 2006, 21 (1-2):71-75

19. Nwanjo H U, Ojiako O A. Investigation of the Potential Health Hazards of Petrol Station Attendants in Owerri Nigeria J. Appl. Sci. Environ. Manage; 2007; 11 (2) $197-200$

20. Marieb, E. N. Human Anatomy and Physiology. 3rd ed. Benjamin and Cummnings Pub Co, California; 1995; 585-611.

21. Iwuanyanwu K.C.P, Onyemaenu C.C, Wegwu M.O and Ayalogu E.O. Haematotoxic Effects of Diets Contaminated with Petroleum Products (Kerosene and Petrol) in Wistar Albino Rats Res. J. Environ. Toxicol; 2010 4: 134-140.

22. Onwurah, I. N. E. Lipid peroxidation and protein oxidation in Azotobacter vinelandii exposed to mercury, silver, crude oil and fenton reagent. Journal of toxic substances;1999; 18(4):167-176 